\title{
Panchimalco: supervivencia y calidad de vida en la comunidad indígena de un pueblo originario
}

\author{
Panchimalco: survival and life quality in the indigenous community \\ of native peoples
}

\author{
Blanca Judith Marroquín de Miguel' \\ Docente \\ judithmarroquín14@hotmail.com
}

http://hdl.handle.net/11298/412

Recibido: 21/07/17 - Aceptado: 15/10/17

\section{Resumen}

Este artículo aborda la situación de los descendientes indígenas de Panchimalco, captados principalmente desde las cofradías y desde la labor de trasmisión cultural y mediante el testimonio de don Félix Ramos. El objetivo principal fue actualizar los datos sobre la sobrevivencia y calidad de vida de la comunidad campesina de ascendencia indígena en Panchimalco, para establecer posibles causas que les estén afectando en su salud y subsistencia de sus costumbres, su lenguaje y sus tradiciones, en el país. Entre los resultados más relevantes se presenta la supervivencia de los pueblos originarios en un porcentaje mínimo, su cultura tiene raíces desde el período colonial, algunos de sus habitantes aún tienen presente los rasgos típicamente característicos de los pueblos originarios, como la vestimenta, la religión y el lenguaje; su situación económica se basa en el trabajo informal y en la recepción remesas familiares; y para la atención de la salud cuentan con una clínica provista por el Ministerio de Salud.

\section{Palabras clave}

El salvador - Historia - Colonia - 1539-1821; Cofradías -

El Salvador; Panchimalco - Historia; Folclor - El Salvador

\section{Abstract}

From a minimalist perspective, this article tackles the current situation of the descendants of the indigenous peoples of Panchimalco, who were mainly contacted from the church cofradías-brotherhoods-- and those working in the passing on of their culture. The testimonial of Don Félix Ramos' also contributed. The main purpose has been that of updating the data on the survival and the quality of life of the peasant community with indigenous ascent in Panchimalco, in order to establish the possible causes affecting their health and the subsistence of their customs, their language and their traditions in the country. Among the most relevant findings, is the fact that the survival of the native peoples conforms a minimal percentage; their culture is rooted in the colonial period; some of its inhabitants still show traces characteristic of the native peoples such as their dress, their religion and their language; their economic situation is based on informal labor and the family remittances they get. Their health services are provided by a clinic administered by the Ministry of Health.

\section{Keywords}

El Salvador - History - The Colonial Period - 1539-1821; Cofradías: brotherhoods - El Salvador; Panchimalco History; Folklore - El Salvador 


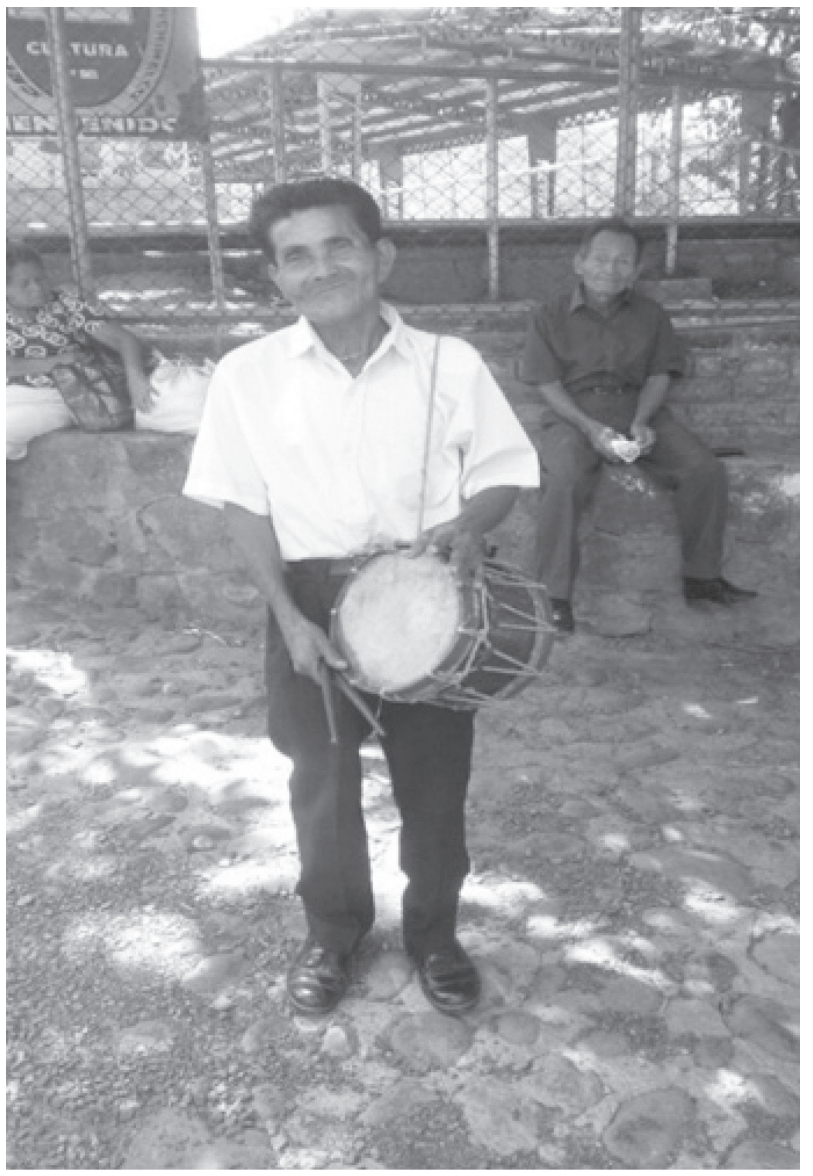

\section{Introducción}

El presente artículo surge de una investigación realizada en la cátedra Realidad Nacional de la Universidad Tecnológica de El Salvador (Utec), tiene motivos humanísticos que buscan rescatar la memoria histórica de los pueblos indígenas en El Salvador, es decir, que artículo pretende visibilizar aquel pueblo que históricamente ha estado presente pese al devenir del tiempo, y sobre todo pese a los esfuerzos por ocultarlo. Aquí queremos enfocarnos en dos factores como la religiosidad popular y la situación social para establecer una relación de causalidad.

Este artículo da a conocer el esfuerzo de los pueblos indígenas por sobrevivir y explicar sobre la "supervivencia", que muy bien puede ser sustituida por "economía de subsistencia", mantener la radicalidad de la expresión supervivencia para crear una mayor conciencia porque la historia no ha estado precisamente a favor de estos pueblos indígenas; también aludiremos al concepto de salud como "calidad de vida", presentando datos cuantificables y una breve descripción del lugar con sus gentes.

Por tanto, en este artículo nos proponemos explorar la relación que hay entre el factor económico y la religiosidad de las comunidades. ¿En qué condiciones económicas o de supervivencia se encuentran las comunidades indígenas? Para explicar la situación de los pueblos indígenas es menester hacer un recorrido histórico.

Los términos con que nos refiramos a ellos no importan: pueblos indígenas, pueblos originarios, poblaciones tribales, indios, pueblos autóctonos, primeros pueblos y otros. Aunque en El Salvador son muy pocos los que aún se pueden llamar indígenas; en el mundo son un grupo social que suman más de 370 millones de personas distribuidas en más de 70 países. Habitaron estas tierras, que ahora llamamos salvadoreñas, mucho antes de la venida de los españoles. Con su trabajo y sudor han contribuido a la construcción de este país. Con su sangre han escrito algunos de los capítulos más tristes de la historia salvadoreña. Su lengua ha enriquecido con numerosos vocablos y topónimos al español que todos hablamos cotidianamente. Su sangre corre por las venas de la mayoría de los salvadoreños como consecuencia del mestizaje del que fueron víctimas durante la Conquista y el coloniaje españoles, que se prolongó con los criollos en el tiempo de la República, sin embargo la Constitución de la República nunca los reconoció, es decir, el Estado salvadoreño los ha ignorado desde su fundación. Siempre los pueblos indígenas han sido invisibles y supervivientes no porque no se vean, sino porque no se les han garantizado sus derechos.

La investigación intenta remitir al esfuerzo de los pueblos indígenas por vivir, por eso queremos hablar de supervivencia; queremos mantener la radicalidad de la expresión porque la historia no ha estado precisamente a favor de estos pueblos, también aludiremos al concepto de salud como "calidad de vida" para presentar datos cuantificables, además de la descripción que exige una mirada general a la problemática social en la que están inmersos los pueblos originarios.

La historia precolombina nos señala aquellas sociedades de los pueblos originarios, a veces imaginadas como un paraíso. Lo cierto es que en ella vemos esfuerzos de supervivencia; sus modos de producción, de comercialización y de organizarse socialmente, que cambian drásticamente con 
la Conquista y colonización después del choque de dos civilizaciones desiguales por las aptitudes guerreristas, armamento de los españoles (recordemos que España llevaba siete siglos de guerra contra los musulmanes). Como resultado, los vencidos tuvieron que someterse al modo de organización de los conquistadores.

Sin embargo, en los cuatrocientos años de colonia los pueblos indígenas siguen vivos, muestran aptitudes de supervivencia, se esfuerzan por hacerse la vida, adaptarse al sistema con el fin de tener un futuro. Segundo Montes decía que habían sobrevivido, al menos, dos pueblos importantes: los nonualcos y los izalcos. Pero actualmente el historiador Carlos Gregorio Bernal señala tres pueblos indígenas: Cojutepeque, izalcos y nonualcos, estos no son los pueblos que hoy conocemos sino tres grandes regiones que pueden apreciarse al final de los siglos de la Colonia española; nunca estos pueblos dejan sus esfuerzos por vivir en contra de la muerte impuesta por sus victimarios.

La historia salvadoreña registra algunos levantamientos indígenas, sin embargo hay una cantidad importante que todavía la historiografía salvadoreña no ha estudiado ni profundizado. El último levantamiento o motín que se registra en 1932, que tiene por epicentro la región de los izalcos. Los indígenas no solo pierden la vida, sino que a los que se salvan se les prohíbe su forma de vida.

No puede dudarse de que estos grupos fueron sectores "subalternos" y que tenían ante sí una lucha radical por vivir bajo el poder de los conquistadores, primero; luego en la Colonia española, y por último, en la construcción del Estado salvadoreño y frente a un gobierno militar, en el martinato.
Por tanto, al constatar el esfuerzo por ocultarlos y sus distintos procesos debemos, pues, observar su supervivencia, relacionando con la calidad de vida. Este tema es uno de los abordados por el doctor Alejandro Dagoberto Marroquín en su estudio sobre Panchimalco, en la que plantea en la introducción la insuficiencia de fuentes y datos históricos referentes a la época prehispánica; sin embargo, se dispone de algunas fuentes de la época colonial, con las que se confirma que debido a la concavidad de la geografía del lugar, este debió ser refundado con motivos guerreristas "ciudad de escudos y banderas".

\section{Materiales y métodos}

A partir de la aproximación a la comunidad y la cofradía de Panchimalco se encontraron a las familias de ascendencia indígena.

Tipo de estudio: trasversal-descriptivo

1. Cuantitativo estadístico: uso de encuestas con el fin de levantar datos y procesarlos en una tabla.

2. Entrevista. Esta es realizada por los estudiantes fue semiestructurada y se procedió a investigar al tata Teófilo (coordinador de las cofradías) y a don Feliz Guzmán (exsecretario de la Asociación Nacional de Indígenas Salvadoreños, Anis).

Participantes: adulto mayor miembro de cofradías, danzas de chapetones e historiantes y de la Anis (originarios de Panchimalco).

\section{Tabla de criterios}

\begin{tabular}{|l|l|}
\hline \multicolumn{1}{|c|}{ Inclusión } & \multicolumn{1}{c|}{ Exclusión } \\
\hline Que viva en Panchimalco. & Que su lugar de residencia sea otro. \\
\hline Que pertenezcan a la tercera edad. & Que no cumpla con la edad establecida. \\
\hline Que sea miembro de una institución o que sea indígena. & Que no pertenezca a ningún grupo reconocido como indígena. \\
\hline
\end{tabular}


Procedimiento: nos aproximamos a los sujetos y entidades gubernamentales, apoyándonos para mejorar la investigación proporcionando guías como medios para vincularnos con la población indígena de Panchimalco.

Instrumento: encuesta realizada a algunos miembros clave de la comunidad de Panchimalco.

\section{Encuesta}

1. ¿Cuáles son las principales tradiciones en Panchimalco?

2. ¿Cómo trasmiten su cultura a sus nuevas generaciones?

3. ¿Qué problemas enfrenta ante la sociedad hoy en día la comunidad?

4. ¿Aún practican el lenguaje náhuat?

5. ¿Reciben apoyo de parte del Gobierno para preservar sus costumbres y tradiciones?
6. ¿Cuál es su ocupación?

7. ¿Los ingresos que reciben alcanzan a cubrir la canasta básica?

8. ¿Qué necesidades observa usted en los hermanos de la cofradía?

9. ¿Es fácil para su familia acceder al sistema de salud pública? 10. ¿Padece de alguna enfermedad?

11. ¿Conocen los derechos de los indígenas?

\section{Resultados}

En la siguiente tabla con su respectiva gráfica se dan a conocer los datos obtenidos en la encuesta realizada a la población de Panchimalco con el fin de saber su estado actual de cultura, economía, educación, salud y seguridad

\section{Tabla de resultados}

\begin{tabular}{|c|c|c|c|}
\hline Preguntas & Sí (\%) & No (\%) & Observación \\
\hline 1. ¿Conocen de la tradición del lugar? & 90 & 10 & \\
\hline $\begin{array}{l}\text { 2. ¿Existe transmisión de cultura a genera- } \\
\text { ciones futuras? }\end{array}$ & 75 & 25 & \\
\hline $\begin{array}{l}\text { 3. ¿Es la economía un problema para las fa- } \\
\text { milias? }\end{array}$ & 60 & 40 & \\
\hline $\begin{array}{l}\text { 4. ¿Es cubierta la canasta básica en Panchi- } \\
\text { malco? }\end{array}$ & 50 & 50 & \\
\hline 5. ¿Cuenta con casa propia? & 65 & 35 & \\
\hline 6. ¿Recibe remesas del extranjero? & 35 & 65 & \\
\hline $\begin{array}{l}\text { 7. ¿Existen carencias?, y menciona cuáles } \\
\text { son las necesidades de las cofradía. }\end{array}$ & 80 & 20 & Voluntariado y ayuda económica \\
\hline $\begin{array}{l}\text { 8. ¿Tiene conocimiento de pandillas en la } \\
\text { zona? }\end{array}$ & 93 & 0,7 & \\
\hline $\begin{array}{l}\text { 9. ¿Padece de alguna enfermedad o de des- } \\
\text { nutrición? }\end{array}$ & 0,3 & 97 & \\
\hline 10. ¿Conoce la lengua náhuat? & 10 & 90 & $\begin{array}{l}\text { Dicha cantidad positiva es hecha valer por } \\
\text { los estudiantes, ya que es una materia de } \\
\text { primero a sexto grado }\end{array}$ \\
\hline
\end{tabular}


La tabla de resultados tiene algunos puntos de interés, como la trasmisión cultural de la tradición, a excepción del idioma Náhuat. La labor de don Félix Ramos de enseñar el Náhuat a alumnos de $1^{\circ}$ a $6^{\circ}$ grado responde a este hecho. También es importante resaltar que el conocimiento de que existen pandillas tenga un $93 \%$. En lo económico, Panchimalco sobrevive por el comercio informal y por la recepción de las remesas. En el rubro del conocimiento de tradiciones culturales, se fomenta en un $90 \%$.

\section{Sobre don Félix Ramos}

\section{Relevancia histórica del personaje}

Anis surge en 1975, adquiere personería jurídica en 1984, fue la primera organización indígena en El Salvador, que tiene sus bases en la zona occidental del país, en los departamentos de Sonsonate y Ahuachapán, es decir, en la zona náhuat.

A pesar de que en 1983 estos indígenas sufrieron una masacre por parte del Ejército nacional en la comunidad de Las Hojas, en la cual murieron 74 indígenas, en estos mismos años los dirigentes de Anis comenzaron a colaborar con el gobierno central, bajo el liderazgo del Partido Demócrata Cristiano. En este período, el Gobierno los apoyó proporcionándoles un local en Sonsonate; se los invitó a participar en el pacto social, una de las políticas centrales de este Gobierno, e incluso se les permitió participar en la directiva del Banco de Fomento Agropecuario. En la época de la Reforma Agraria fue cuando la participación de don Félix Ramos adquiere vigencia. Siendo un joven secretario de dicha organización, don Félix da testimonio oral de las discusiones acaloradas en el seno de esta, también de la persecución que sufrió por parte de la Guardia Nacional; es exiliado en la década de los años 80 en México.

Con el desarrollo del conflicto político-militar, Anis va adoptando una posición de izquierda, e incluso llega a colaborar directamente con el movimiento revolucionario. De hecho, en 1989 el Gobierno intervino militarmente el local de Anis y sus dirigentes fueron perseguidos, lo cual contrasta con la idea general que tiene la historiografía nacional: "Después de 1932 los indígenas se sumen en un silencio represivo por la persecución de los cuerpos de seguridad". Es en esa época cuando se da el rompimiento definitivo de Anis con el Gobierno central. Se puede afirmar que, incluso en la década de los 80, los indígenas son perseguidos. Quizás habría de decir que estos pobladores no están aglomerados en una sola etnia, sino en una organización de pretensiones políticas. Si bien es cierto no participan desde su identidad en los movimientos de insurgencia, pese a que hay guerrillas en lo que fueron los pueblos indígenas.

\section{Sobre el tata Teófilo y las cofradías}

Conocido por todas las personas del pueblo como tata Teofilo, es muy querido, admirado, respetado y reconocido por todo el pueblo de Panchimalco; es también quien tiene a su cargo, como coordinador, que las tradiciones no desaparezcan en los pueblos como estos, guiando e inculcándolas de generación en generación; a su cargo tiene 15 capitanes y 35 mayordomos; el número de priostes depende de cuántos tenga la imagen a la cual se celebra. Esta tradición tiene su origen, según el tata Teófilo, en la Iglesia católica. Su inicio en las cofradías, nos dice tata Teófilo, es a raíz de que su padre le inculcó los principios y costumbres que él practica; quien sigue siendo un prioste de la iglesia El Rosario. En aquel tiempo lo acompañaba en todo momento; $y$ al fallecer lo deja nombrado como prioste. Tata Teófilo nos manifiesta que su padre fue muy reconocido, al igual que él, y que falleció cuando él tenía 40 años de edad (en esta breve descripción podemos observar la "trasmisión" generacional, es decir, por "linaje").

En Mesoamérica se da una continuidad básica de los principios estructurales relacionados con el sistema de escala entre la época prehispánica y la colonial, siendo la modificación más significativa su cambio de función al pasar de ser un mecanismo para la selección del personal dirigente, o la validación de méritos heredados en una sociedad estratificada independiente, a uno para el reparto de responsabilidades entre los miembros de un segmento no estratificado (el campesino) de una sociedad más amplia: la sociedad colonial. Estaríamos ante un caso de gran similitud y continuidad en algunos aspectos de la estructura social junto con un cambio radical en las formas culturales; el núcleo estructural del sistema se mantiene desde lo prehispánico hasta la actualidad, si bien el sistema de cargos es primariamente de origen europeo (las cofradías tendrían origen en España), pero su carácter jerárquico y la fusión de autoridad civil y religiosa son elementos de la organización social precolombina.

El hecho concreto de que la cofradía de Panchimalco haya adquirido cierta "legitimidad", ya que el prioste general es 
nombrado por el alcalde del pueblo, indica que en términos sociológicos puede conceptualizarse como un grupo subalterno. Con respecto a su situación, no reciben ningún aporte económico para mantener la cofradía; cada una tiene un gasto próximo de 400 dólares, cantidad que además debe reponerse al hacer el traspaso a otro prioste; Por otra parte, no siempre están seguros del apoyo o asistencia por parte de la iglesia católica. La situación social de las cofradías se ubica como religiosidad popular, que no siempre está en consonancia con la doctrina católica y su calendario litúrgico, dicha "religiosidad" no es la oficial de la teología de la Iglesia católica, no en todos los casos de cambio de párroco son asumidas.

Acerca de las cofradías, Marroquín nos dice que parten de actitudes religiosas de tipo netamente tradicional (culto a los santos). Encontramos arraigo a las viejas generaciones y al sentido comunitario. Para Marroquín, son "grandes convivialidades organizadas a través de las típicas cofradías".

\section{Conclusión y discusión}

Panchimalco es uno de los municipios que mejor representa la supervivencia de los pueblos originarios; su cultura tiene raíces en el período colonial, algunos de sus habitantes aún tienen presente los rasgos típicamente característicos de dichos pueblos. Desafortunadamente, nuestros pueblos indígenas han perdido casi todas las manifestaciones tangibles de su identidad, como la vestimenta, y las intangibles, como la religión y el lenguaje, que encontramos en otras poblaciones indígenas alrededor del mundo (no en todas). Esto no quiere decir, sin embargo, que han dejado de existir como grupos étnicos.

Cualquier persona que haya trabajado con los indígenas salvadoreños sabe lo difícil que es identificarlos y diferenciarlos de otros grupos sociales. Esto no significa que sea imposible. Se han propuesto algunos criterios que pueden servir de base para identificar al indígena del no indígena. Autores como Marroquín (1975) y Mac Chapín han propuesto parámetros antropomorfos y socioeconómicos para identificarlos, tales como el color de piel y la pobreza heredada, respectivamente. En realidad, estos criterios antropomorfos son discutibles, pues debido al mestizaje el color de piel moreno lo tienen tanto indígenas como ladinos, y la pobreza en este país es generalizada. Por tanto, los pueblos originarios siguen presentes pese al devenir de la historia; y queda mucho por investigar.

\section{Referencias}

Historia de El Salvador, (Educación, 1994)

Godelier (1974). Antropología y Economía. Barcelona, España: Editorial Anagrama.

Marroquín Joachin, J.M. (septiembre, 2009). “Los fenómenos que están incidiendo en la tradición danzaria (Educación, 1994) de los historiantes de Panchimalco". Recuperado de http://biblioteca.utec.edu.sv/siab/ virtual/tesis/48995.pdf

Marroquín,A.D. (1974). Panchimalco. Investigación Sociológica. San Salvador, El Salvador: Editorial Universitaria. 